\title{
BMJ Open Time to recovery from severe acute malnutrition and its predictors: a multicentre retrospective follow-up study in Amhara region, north- west Ethiopia
}

\begin{abstract}
Adhanom Gebreegziabher Baraki (D) ,' Temesgen Yihunie Akalu, ${ }^{1}$ Haileab Fekadu Wolde, ${ }^{1}$ Wubet Worku Takele (D) ,2 Worku Nigussu Mamo, ${ }^{3}$ Behailu Derseh, ${ }^{4}$ Hanna Demelash Desyibelew, ${ }^{5}$ Abel Fekadu Dadi ${ }^{1}$
\end{abstract}

To cite: Baraki AG, Akalu TY, Wolde HF, et al. Time to recovery from severe acute malnutrition and its predictors: a multicentre retrospective followup study in Amhara region, north-west Ethiopia. BMJ Open 2020;10:e034583. doi:10.1136/ bmjopen-2019-034583

- Prepublication history for this paper is available online. To view these files, please visit the journal online (http://dx.doi org/10.1136/bmjopen-2019034583).

Received 02 October 2019 Revised 09 January 2020 Accepted 13 January 2020
Check for updates

(C) Author(s) (or their employer(s)) 2020. Re-use permitted under CC BY-NC. No commercial re-use. See rights and permissions. Published by BMJ.

For numbered affiliations see end of article.

Correspondence to Adhanom Gebreegziabher Baraki; adsh04@gmail.com

\section{ABSTRACT}

Objectives This study aimed to determine the time to recovery from severe acute malnutrition (SAM) and its predictors in selected public health institutions in Amhara Regional State, Ethiopia.

Design An institution-based retrospective follow-up study was conducted using data extracted from 1690 patient cards from September 2012 to November 2016.

Setting Selected government health institutions in the Amhara region, Ethiopia.

Participants Children treated in therapeutic feeding units for SAM were included.

Outcome measures Time to recovery from SAM. Results One thousand and fifty children have recovered from SAM, $62.13 \%$ (95\% Cl 59.8\% to $64.5 \%$ ). The median time to recovery was 16 days $(\mathrm{IQR}=11-28)$. Female gender (adjusted HR (AHR) $=0.81,95 \% \mathrm{Cl} 0.67$ to 0.98 ), oedematous malnutrition (AHR=0.74 95\% $\mathrm{Cl} 0.59$ to 0.93 ), pneumonia (AHR=0.66, $95 \% \mathrm{Cl} 0.53$ to 0.83 ), tuberculosis (AHR $=0.53,95 \% \mathrm{Cl} 0.36$ to 0.77 ), HIV/AIDS (AHR=0.47, $95 \% \mathrm{Cl} 0.28$ to 0.79 ), anaemia (AHR=0.73, $95 \% \mathrm{Cl} 0.60$ to $0.89)$ and receiving vitamin $\mathrm{A}(\mathrm{AHR}=1.43,95 \% \mathrm{Cl} 1.12$ to 1.82 ) were notably associated with time to recovery. Conclusions The time to recovery in this study was acceptable but the proportion of recovery was far below the minimum standard. Special emphasis should be given to the prevention and treatment of comorbidities besides the therapeutic feeding. Supplementing vitamin A would also help to improve the recovery rate.

\section{INTRODUCTION}

Severe acute malnutrition (SAM) is the most extreme and visible form of undernutrition. This nutritional disorder is characterised by the presence of at least one of the following clinical parameters: bilateral oedema of nutritional origin and/or severe wasting (weight for height<-3SD), and/or mid-upper arm circumference (MUAC) $<11 \mathrm{~cm}$. A child with SAM requires urgent treatment in order to prevent further damage and facilitate survival
Strengths and limitations of this study

- A relatively large sample size was used in this study.

- We have tried all possible models to come up with a precise estimate.

- The data used were secondary data; therefore this study shares limitations of secondary data collection.

time. About two-thirds of children with SAM live in Asia and almost a third live in Africa. ${ }^{1}$ Malnutrition directly or indirectly accounts for $35 \%$ of deaths among children under 5 years of age. ${ }^{2}$

The burden of severe malnutrition is not evenly distributed and Ethiopia is one of those countries severely affected by it. Malnutrition by itself or as a comorbidity accounts for $57 \%$ of deaths under 5 years. ${ }^{34}$ The negative consequences of malnutrition follow the child for his/her entire life. In addition to the immediate effects of malnutrition on a child, Ethiopia loses around $16.5 \%$ of its gross domestic product per annum because of the long-term effects of childhood malnutrition. ${ }^{5}$

The minimum proportion of children with SAM that are expected to recover after therapy is $75 \%{ }^{6}$ But Ethiopia falls short meeting the standard and the recovery rates vary between $51.9 \%$ and $88.4 \% .{ }^{4-10}$ The recommended time to recovery among children on therapeutic feeding is less than 1 month, ${ }^{11}$ there are also no uniform findings in this regard.

Several factors affect the recovery rate from SAM; these include sex of the child, age, educational status of the mother, type of malnutrition, nutritional supplements while on treatment, and presence of comorbidities like tuberculosis and HIV. ${ }^{812-14}$ 
The average recovery time and its important predictors are not well established in the Amhara region in a comprehensive way. In addition, it has been suggested that follow-up studies are crucial to investigate clinical problems.

Therefore, this study was conducted to determine the median time to recovery among children with SAM and identify important predictors that could affect the survival time. The findings from this study would help in reducing extended time in therapeutic feeding units and its actual recovery rate.

\section{METHODS}

\section{Study design and setting}

A retrospective follow-up study was conducted from September 2012 to November 2016 in selected government health institutions in the Amhara region, northwest Ethiopia. These institutions are: Felege Hiwot Referral Hospital, Debre Berhan Referral Hospital, University of Gondar comprehensive specialised hospital, selected health centres and health posts in rural North Gondar, Amhara Regional State, Ethiopia. The paediatric department in these health institutions is among the main inpatient departments where children with complicated malnutrition are treated, whereas the children with uncomplicated SAM are treated as outpatients. All institutions use the same SAM treatment protocol.

\section{Study population and variables}

All children with SAM, aged less than 59 months, treated between September 2012 and November 2016, were our study population. SAM was diagnosed using at least one of the following clinical criteria: bilateral oedema of nutritional origin, severe wasting (weight for height $<-3$ $\mathrm{SD})$ or MUAC $<11 \mathrm{~cm}$ for children older than 6 months, whereas for infants the diagnostic criteria used was: the infant is too weak or feeble to suckle effectively or weight for length $<70 \%$ and/or presence of bilateral oedema. A child older than 6 months is declared cured based on

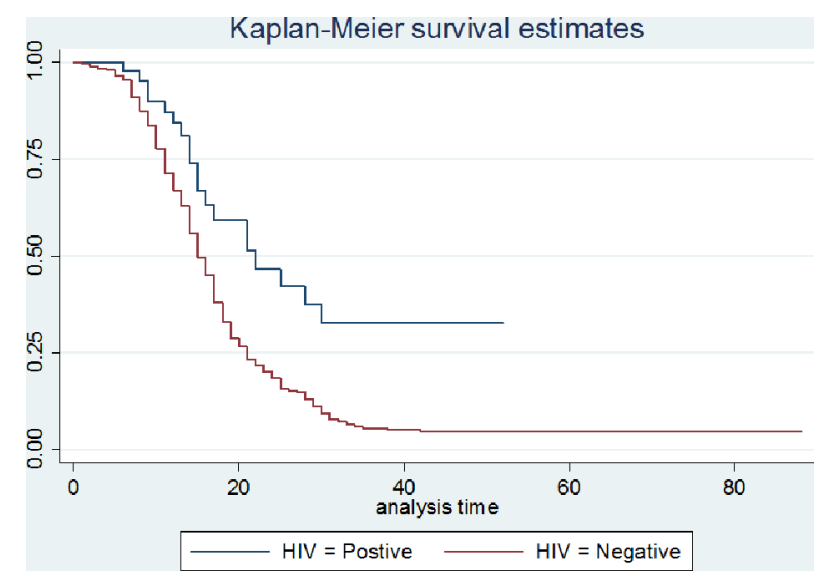

Figure 1 Kaplan-Meier survival estimate for time to recovery among children treated for severe acute malnutrition (SAM in Amhara region, subgrouped by HIV status (2016)). the SAM treatment protocol as weight for length $\geq 85 \%$ or weight for height $\geq 85 \%$ on more than one occasion (two days for inpatients, 2 weeks for outpatients), and no oedema for 10 days (inpatient) or 14 days (outpatient). Cure is declared for infants less than 6 months old when it is clear that he/she is gaining weight on breast milk alone after the supplemented suckling technique has been used, there is no medical problem, and the mother has been adequately supplemented with vitamins and minerals so that she has accumulated body stores of nutrients. ${ }^{15}$ Time to recovery was defined as the time from the start of treatment to the time the child was cured. Censored was declared when the outcome is not observed, which included death, drop out of treatment, transferred to another treatment centre and did not develop the event until the completion of the study period. Data on independent variables: age, sex, residence, breastfeeding status, vaccination status, treatment duration, type of malnutrition, routine medications provided and presence of comorbidities were also collected.

\section{Sample size and sampling procedures}

Records of 1690 children under 5 years of age treated for SAM, which were collected through retrospective review in the following therapeutic feeding units in Amhara region were merged: Felege Hiwot Referral Hospital=401, Debre Berhan Referral Hospital=373, Gondar University Referral Hospital=527, and from rural Gondar health institutions $=389$. Simple random sampling was used to select the record of each child from the therapeutic feeding unit registration logbook from each hospital based on their unique identification number, and then their charts were reviewed. As the study was conducted through a review of records, no consent was asked from the mothers or caregivers of the study subjects. The confidentiality and privacy of the patient records were ensured by avoiding names and identification numbers from the extraction form and codes were used instead.

\section{Data collection tools and procedures}

A structured data extraction form was developed and used to extract information from patient cards. A 2-day practical training was given for data collectors on the objectives of the study, how to review registration logbooks and the patient's chart, and to maintain the confidentiality of the data. Health professionals working at a paediatric ward extracted the required data from patient charts under supervision.

\section{Data processing and analysis}

The data were checked for inconsistencies, coding error, completeness, accuracy, clarity and missing values. Summary measures such as counts, percentages, medians, IQRs, means and SD were calculated. The Kaplan-Meier survival method and log-rank test curves were applied to estimate the probability of recovery at a given time and to compare the survival curve, respectively. Cox proportional hazards assumption was checked both graphically 
and using the Schoenfeld residuals test. Model selection was done using Akaike Information Criteria (AIC) and Bayesian Information Criteria. The parametrical survival analysis, Weibull regression, was used to identify predictors of time to recovery. Model goodness of fit was checked using Cox Snell residual test. Adjusted HRs (AHRs) with their respective $95 \%$ CIs were estimated and a value of $p$ less than 0.05 was used to declare the presence of a significant association. All statistical analysis was done using Stata V.14.0.

\section{Patient and public involvement}

Since we have used secondary data/chart review, patients or the public were not involved during identifying the research question or during the design and conduct of the study.

\section{RESULTS}

A total of 1690 children with SAM charts were reviewed. From the total, $914(54.08 \%)$ were girls. The majority, $1148(67.93 \%)$, of these children was less than 2 years of age. Most of the children, $808(61.35 \%)$, were rural residents. Nine hundred thirty-two $(80.21 \%)$ and 1337 $(79.11 \%)$ children were fully vaccinated and breast fed, respectively. The majority of the children, 1241 (73.43\%), had non-oedematous malnutrition. Regarding comorbidities, $575(34.02 \%)$ of the children had diarrhoea. One hundred and seven $(8.22 \%)$ and $54(4.15 \%)$ children had tuberculosis and HIV, respectively (table 1 ).

\section{Time to recovery of children with SAM}

A total of 1050 children recovered from SAM, making it a recovery rate of $62.13 \%$ (95\% CI $59.8 \%$ to $64.5 \%$ ). The recovery rate for oedematous malnutrition was $57.6 \%$ (95\% CI $52.9 \%$ to $62.2 \%$ ) whereas the recovery rate for non-oedematous malnutrition was $63.8 \%$ (95\% CI $61.1 \%$ to $66.5 \%$ ).

The median time to recovery was 16 days ( $\mathrm{IQR}=11-$ 28). A total of $578(34.2 \%)$ had rapid catch-up growth $(>10 \mathrm{~g} / \mathrm{kg} /$ day $)$ whereas $688(40.71 \%)$ and $424(25.09 \%)$ had medium $(5-10 \mathrm{~g} / \mathrm{kg} /$ day $)$ and poor $(<5 \mathrm{~g} / \mathrm{kg} /$ day $)$ catch-up growth in the treatment time, respectively. There was a significant difference in the time of recovery between HIV-free and HIV-positive children, where HIVnegative children recovered faster (figure 1). A significant difference in the recovery rate among the two groups is also seen by the log-rank test $\chi^{2}=14.06$ and $p=0.0002$.

\section{Factors affecting time to recovery}

The overall Schoenfeld global test of the full model has met the proportional hazards assumption $\left(\chi^{2}=17.5\right.$, $\mathrm{p}=0.0940)$. We have also compared the parametrical survival analysis with different distributions; these were further compared using their AIC value. The presence of a significant difference in the recovery time among treatment centres was considered by fitting the shared frailty model but the shared frailty term $(\theta)$ was not significant
Table 1 Baseline characteristics of children with severe acute malnutrition (SAM) in Amhara region, north-west Ethiopia, 2016

\begin{tabular}{lcc}
\hline Variables & Frequency & Percentage \\
\hline Treatment facility & & \\
\hline Felege Hiwot Referral Hospital & 401 & 23.73 \\
$\begin{array}{l}\text { Debre Berhan Referral Hospital } \\
\text { Gondar University Referral }\end{array}$ & 373 & 22.07 \\
$\begin{array}{l}\text { Hospital } \\
\text { North Gondar rural health } \\
\text { institutions }\end{array}$ & 389 & 31.18 \\
\hline
\end{tabular}

Sex

\begin{tabular}{lrr} 
Male & 776 & 45.92 \\
Female & 914 & 54.08 \\
Age & & \\
$\quad<2$ years & 1148 & 67.93 \\
$\quad 22$ years & 542 & 32.07 \\
$\begin{array}{l}\text { Residence } \\
\text { Rural }\end{array}$ & \\
$\quad$ Urban & 808 & 61.35 \\
Breast feeding & 509 & 38.65 \\
No & & \\
Yes & 353 & 20.89 \\
\hline
\end{tabular}

Vaccination status

$\begin{array}{crc}\text { Unvaccinated } & 230 & 19.79 \\ \text { Vaccinated } & 932 & 80.21 \\ \text { Oedema } & & \\ \text { Present } & 449 & 26.57 \\ \text { Absent } & 1241 & 73.43\end{array}$

\begin{tabular}{lrr} 
Diarrhoea & & \\
No & 1115 & 65.98 \\
Yes & 575 & 34.02 \\
\hline $\begin{array}{l}\text { Pneumonia } \\
\text { No }\end{array}$ & \\
Yes & 864 & 66.41 \\
Anaemia & 437 & 33.59 \\
$\quad$ No & & \\
Yes & 762 & 58.57 \\
Tuberculosis & 539 & 41.43 \\
Yes & & \\
No & 107 & 8.22 \\
\hline
\end{tabular}

HIV status

\begin{tabular}{lrr} 
Positive & 54 & 5.75 \\
Negative & 885 & 94.25 \\
Antibiotics & & \\
Given & 657 & 50.31 \\
Not given & 649 & 49.69 \\
Folic acid & & \\
Given & 859 & 65.82 \\
Not given & 446 & 34.18 \\
\hline
\end{tabular}

Continued 


\begin{tabular}{|lll|}
\hline Table 1 & Continued & \\
\hline Variables & Frequency & Percentage \\
\hline Vitamin A & & \\
Given & 686 & 52.53 \\
Not given & 620 & 47.47 \\
\hline
\end{tabular}

showing no significant difference among the treatment centres.

In the bivariable Weibull regression analysis, sex, age, residence, breastfeeding status, type of malnutrition, pneumonia, anaemia, tuberculosis, HIV status and receiving vitamin A were selected for multivariable analysis with $\mathrm{p}<0.2$ and their crude HR was estimated. In the multivariable analysis, AHR of sex, type of malnutrition, pneumonia, anaemia, tuberculosis, HIV status and vitamin A supplement were estimated as independent predictors of time to recovery with a value of $\mathrm{p}<0.05$.

The recovery time was delayed by $19 \% \quad(\mathrm{AHR}=0.81$, $95 \%$ CI 0.67 to 0.98 ) among female children as compared with male. Children with the oedematous form of malnutrition had slower recovery as compared with their nonoedematous counterparts (AHR $=0.74,95 \%$ CI 0.59 to 0.93). Patients with pneumonia had a $34 \%$ lower pace of recovery when compared with those without pneumonia (AHR $=0.66,95 \%$ CI 0.53 to 0.83 ). Recovery was delayed among children who had tuberculosis $(\mathrm{AHR}=0.53,95 \% \mathrm{CI}$ 0.36 to 0.77 ), HIV infection (AHR $=0.47,95 \%$ CI 0.28 to 0.79 ) and anaemia (AHR $=0.73,95 \%$ CI 0.60 to 0.89 ) as compared with their normal counterparts. Whereas

Table 2 Predictors of time to recovery among children with severe acute malnutrition (SAM) in Amhara regional state, 2016

\begin{tabular}{|c|c|c|c|c|}
\hline \multirow[b]{2}{*}{ Variables } & \multicolumn{2}{|c|}{ Recovery } & \multirow[b]{2}{*}{ Crude HR $(95 \% \mathrm{Cl})$} & \multirow[b]{2}{*}{ Adjusted HR $(95 \% \mathrm{Cl}$} \\
\hline & Event & Censored & & \\
\hline \multicolumn{5}{|l|}{ Sex } \\
\hline Female & 555 & 358 & 0.91 (0.80 to 1.02$)$ & $0.81(0.67 \text { to } 0.98)^{\star}$ \\
\hline \multicolumn{5}{|l|}{ Age } \\
\hline$\geq 24$ months & 344 & 198 & 1.17 (1.03 to 1.34$)$ & $0.91(0.75$ to 1.11$)$ \\
\hline \multicolumn{5}{|l|}{ Residence } \\
\hline Rural & 507 & 301 & 1 & 1 \\
\hline Urban & 338 & 170 & 0.64 (0.56 to 0.74$)$ & 1.23 (0.99 to 1.52$)$ \\
\hline \multicolumn{5}{|l|}{ Breast fed } \\
\hline No & 792 & 449 & 1 & 1 \\
\hline Yes & 258 & 190 & 0.98 (0.93 to 1.23$)$ & $0.74(0.59 \text { to } 0.93)^{*}$ \\
\hline \multicolumn{5}{|l|}{ Pneumonia } \\
\hline Absent & 552 & 311 & 1 & 1 \\
\hline Present & 244 & 193 & 0.73 (0.63 to 0.85$)$ & $0.66(0.53 \text { to } 0.83)^{\star}$ \\
\hline \multicolumn{5}{|l|}{ Anaemia } \\
\hline Not anaemic & 489 & 272 & 1 & 1 \\
\hline Anaemic & 307 & 232 & 0.77 (0.67 to 0.89 ) & $0.73(0.60 \text { to } 0.89)^{*}$ \\
\hline \multicolumn{5}{|l|}{ Vitamin A } \\
\hline Not given & 364 & 255 & 1 & 1 \\
\hline Given & 476 & 210 & 2.43 (2.11 to 2.80$)$ & $1.43(1.12 \text { to } 1.82)^{\star}$ \\
\hline
\end{tabular}

${ }^{*}$ P-value $<0.05$ 
children who received vitamin A had $43 \%$ faster recovery as compared with children who did not $(\mathrm{AHR}=1.43$, 95\% CI 1.12 to 1.82 ) (table 2).

\section{DISCUSSION}

This study was conducted to determine the time to recovery from SAM and its predictors. The median time to recovery was 16 days. Sex of the child, type of malnutrition, pneumonia, anaemia, tuberculosis, HIV status and vitamin A supplementation were independent predictors of time to recovery.

Even though the average length of stay in therapeutic centres is longer than a couple of studies conducted in Ethiopia in Wolisso (14 days), and Debre Markos and Finote Selam (11 days), ${ }^{16} 17$ it was still acceptable according to the WHO recommendation, which is an average of 30 days. ${ }^{11}$ The recovery time was also faster when compared with several studies conducted in southern Ethiopia, (22 days (oedematous) and 29 days (non-oedematous)), Shebedibo woreda (35 days) ${ }^{18}{ }^{19}$ Mekelle (17 days $)^{20}$ and Zambia (24 weeks). ${ }^{21}$ The possible reason for this discrepancy could be related to the difference in sociodemographic characteristics among the participants and/ or the difference in the magnitude of comorbidities and adherence to the standard treatment protocol.

Female children had slower recovery as compared with male. This finding is supported by a study conducted in Bangladesh. $^{12}$ The possible reason in this study could be due to a higher proportion of comorbidities such as diarrhoea $(35.34 \%)$ and lower vaccination status of girls $(20.44 \%)$ than boys.

The recovery time among children with oedematous malnutrition was delayed by $26 \%$ as compared with children with marasmus. This finding is supported by other studies conducted in Bahir Dar, ${ }^{13}$ Woldia ${ }^{9}$ and India, ${ }^{22}$ implying that children with kwashiorkor and a mixed form of malnutrition are at risk of delayed recovery than children with marasmus alone. This could be due to the fact that these forms of malnutrition are primarily ascribed to protein deficiency. Therefore children with protein deficiency could have poor immunity, high fluid retention, poor appetite and poor hormonal secretion. As a result, they feed poorly, develop metabolism problems, contract various infections and may end up with delayed recovery. ${ }^{13}$

Children with comorbidities such as anaemia, tuberculosis, HIV/AIDS and pneumonia had slower recovery as compared with those without. This is stated in the previous study as children with comorbidities, in general, have a delayed recovery. ${ }^{8}$ The slower recovery rate among patients with HIV/AIDS, in particular, is supported by several other studies. ${ }^{141617}$ The aforementioned infectious diseases leave these patients at a higher risk of developing a critical illness. This is because, first, infectious diseases increase the nutrition requirement, which causes poor survival as a result of poor intake. Second, these communicable diseases cause micronutrient deficiency following poor gastrointestinal absorption as a result of diarrhoea and gastrointestinal erosion and even microorganisms could compete with patients' cells by consuming nutrients. Studies have shown those micronutrients are indispensable to boost immunity and accelerate survival time. Furthermore, these nutrients are required to synthesise protein and other macronutrients, which could accelerate the recovery time. ${ }^{162324}$ Considering all these together, it is possible to draw an inference that children with SAM with medical complications unfortunately cannot recover earlier than those without SAM.

Children who received vitamin A supplement had a faster recovery rate than the non-supplemented children. The finding is supported by another study conducted in Ethiopia. ${ }^{13}$ Vitamin A supplement was found to reduce all causes of childhood mortality ${ }^{25}$ thereby increasing the recovery rate.

This study has used a relatively large data set which results in a better estimate of the magnitude of recovery and the factors affecting it. Being a retrospective study we were unable to find some important variables that should be considered to identify predictors.

\section{CONCLUSION}

This multicentre study assessed time to recovery from SAM in Amhara region using a relatively large sample size and has put forward a precise estimate of its predictors. Time to recovery in the study area was acceptable as compared with the global cut-off standards, but the proportion of those recovered remains low. According to this study, boys, and those who received vitamin A had a faster recovery rate compared with girls, and those who did not receive vitamin A supplementation. On the contrary, children with comorbidities such as HIV, tuberculosis, pneumonia and anaemia had decreased recovery time. Special emphasis should be given to prevent and treat comorbidities besides therapeutic feeding. Supplementing vitamin A whenever indicated would also be helpful for faster recovery.

\section{Author affiliations}

${ }^{1}$ Department of Epidemiology and Biostatistics, Institute of Public Health, College of Medicine and Health Sciences, University of Gondar, Gondar, Ethiopia

${ }^{2}$ Department of Community Health Nursing, School of Nursing, College of Medicine and Health Sciences, University of Gondar, Gondar, Ethiopia

${ }^{3}$ Nutrition, Abrhajira Primary Hospital, West Gondar Zone, Gondar, Ethiopia

${ }^{4}$ Department of Public Health, College of Health Sciences, Debre Berhan University, Gondar, Ethiopia

${ }^{5}$ Department of Public Health Nutrition, College of Medicine and Health Sciences, Bahirdar University, Bahir Dar, Ethiopia

Acknowledgements The authors thank the data collectors and friends who contributed to this work.

Contributors AGB, TYA, HFW, WNM, WWT, BD, HDD and AFD conceived and designed the study, acquired, analysed and interpreted data, prepared the manuscript and approved the final manuscript.

Funding The authors have not declared a specific grant for this research from any funding agency in the public, commercial or not-for-profit sectors.

Competing interests None declared. 
Patient consent for publication Not required.

Ethics approval Ethics approval was obtained from the ethical review committee of the College of Medicine and Health Sciences, University of Gondar, and also from the respective hospitals.

Provenance and peer review Not commissioned; externally peer reviewed.

Data availability statement Data are available upon reasonable request. Access to data upon which the results are based can be provided upon reasonable request to the corresponding author.

Open access This is an open access article distributed in accordance with the Creative Commons Attribution Non Commercial (CC BY-NC 4.0) license, which permits others to distribute, remix, adapt, build upon this work non-commercially, and license their derivative works on different terms, provided the original work is properly cited, appropriate credit is given, any changes made indicated, and the use is non-commercial. See: http://creativecommons.org/licenses/by-nc/4.0/.

\section{ORCID iDs}

Adhanom Gebreegziabher Baraki http://orcid.org/0000-0002-3488-8584

Wubet Worku Takele http://orcid.org/0000-0003-3121-5808

\section{REFERENCES}

1 UNICEF. Severe acute malnutrition, 2019. Available: https://www. unicef.org/nutrition/index_sam.html [Accessed 20 Aug 2019].

2 WHO. Severe acute malnutrition, 2019. Available: https://www.who. int/nutrition/topics/malnutrition/en/

3 World Health Organization and UNICEF. Community-Based management of severe acute malnutrition: a joint statement by the world Health organization, the world food programme, the United nations system standing Committee on nutrition and the United nations children's fund, 2007.

4 Shanka NA, Lemma S, Abyu DM. Recovery rate and determinants in treatment of children with severe acute malnutrition using outpatient therapeutic feeding program in Kamba district, South West Ethiopia. J Nutr Disorders Ther 2015;5.

5 Federal Democratic Republic of Ethiopia. The cost of hunger in Ethiopia: implications for the growth and transformation of Ethiopia, 2013. Available: https://reliefweb.int/report/ethiopia/cost-hungerethiopia-implications-growth-and-transformation-ethiopia [Accessed 21 Aug 2019].

6 The Sphere Project. Humanitarian charter and minimum standards in humanitarian response 2011.

7 Mekonnen Let al. Severity of malnutrition and treatment Responsesin Underfive children in Bahir Dar Felegehiwotreferal Hospital Northwest Ethiopia. Aca J Nutr 2013;2:31-8.

8 Jarso H, Workicho A, Alemseged F. Survival status and predictors of mortality in severely malnourished children admitted to Jimma university specialized Hospital from 2010 to 2012, Jimma, Ethiopia: a retrospective longitudinal study. BMC Pediatr 2015;15:1.

9 Chane T, Oljira L, Atomesa GE, et al. Treatment outcome and associated factors among Under-Five children with severe acute malnutrition admitted to therapeutic feeding unit in Woldia Hospital, North Ethiopia. J Nutr Food Sci 2014;04.
10 Teferi E, Lera M, Sita S, et al. Treatment outcome of children with severe acute malnutrition admitted to therapeutic feeding centers in southern region of Ethiopia. Ethiopian Journal of Health Development 2010;24.

11 World Health Organization and the United Nations Children's Fund. Who child growth standards and the identification of severe acute malnutrition in infants and children. Geneva, 2009.

12 Ahmed AU, Ahmed TU, Uddin MS, et al. Outcome of standardized case management of under- 5 children with severe acute malnutrition in three hospitals of Dhaka City in Bangladesh. Bangladesh Journal of Child Health 2013;37:5-13.

13 Desyibelew HD, Fekadu A, Woldie H. Recovery rate and associated factors of children age 6 to 59 months admitted with severe acute malnutrition at inpatient unit of Bahir Dar Felege Hiwot referral hospital therapeutic feeding unite, Northwest Ethiopia. PLoS One 2017;12:e0171020.

14 Collins S, Dent N, Binns P, et al. Management of severe acute malnutrition in children. The Lancet 2006;368:1992-2000.

15 Chamois S, Golden M, Grellety Y. Ethiopia protocol for the management of severe acute malnutrition, 2007.

16 Banbeta A, Seyoum D, Belachew T, et al. Modeling time-to-cure from severe acute malnutrition: application of various parametric frailty models. Arch Public Health 2015;73:6.

17 Mekuria G, Derese T, Hailu G. Treatment outcome and associated factors of severe acute malnutrition among $6-59$ months old children in Debre Markos and Finote Selam hospitals, Northwest Ethiopia: a retrospective cohort study. BMC Nutr 2017;3:42.

18 Gebremichael DY. Predictors of nutritional recovery time and survival status among children with severe acute malnutrition who have been managed in therapeutic feeding centers, southern Ethiopia: retrospective cohort study. BMC Public Health 2015;15:1.

19 Mengesha MM, Deyessa N, Tegegne BS, et al. Treatment outcome and factors affecting time to recovery in children with severe acute malnutrition treated at outpatient therapeutic care program. Glob Health Action 2016;9:30704.

20 Gebremichael M, Bezabih AM, Tsadik M. Treatment outcomes and associated risk factors of severely malnourished under five children admitted to therapeutic feeding centers of Mekelle City, Northern Ethiopia. OAlib 2014;01:1-9.

21 Moramarco S, Amerio G, Ciarlantini C, et al. Community-Based management of child malnutrition in Zambia: HIV/AIDS infection and other risk factors on child survival. Int J Environ Res Public Health 2016;13. doi:10.3390/ijerph13070666. [Epub ahead of print: $01 \mathrm{Jul}$ 2016].

22 Singh K, Badgaiyan N, Ranjan A, et al. Management of children with severe acute malnutrition: experience of nutrition rehabilitation centers in Uttar Pradesh, India. Indian Pediatr 2014;51:21-5.

23 Bachou H, Tylleskär T, Downing R, et al. Severe malnutrition with and without HIV-1 infection in hospitalised children in Kampala, Uganda: differences in clinical features, haematological findings and CD4+ cell counts. Nutr J 2006;5:27.

24 Macallan DC, tuberculosis Min. Malnutrition in tuberculosis. Diagn Microbiol Infect Dis 1999;34:153-7.

25 Ahmed T, Hossain M, Sanin KI. Global burden of maternal and child undernutrition and micronutrient deficiencies. Ann Nutr Metab 2012;61 Suppl 1:8-17. 